\title{
Description Methods for Image Records Using Access to Memory (Atom) System for Better Records Retrieval
}

\author{
Muhammad Usman Noor* \\ Vocational Education Program, Universitas Indonesia \\ *Email: musmannbox@gmail.com
}

\begin{abstract}
The ease of producing digital photos creates more and more photo archives. Not all digital photos become archive photos, only photos that have historical value. Digital photo archives that naturally include one electronic archive require special management. The management of a good photo archive will provide many benefits to the institution, such as the ease of retrieval and will function as the memory of the institution. One way of managing the appropriate photo archive according to these principles is to use a filing information system that has applied standard metadata for arispnya description. This paper uses literature studies as a method. Atom archival software is a system of archival information that has applied standard metadata archives and can be used as a means to manage digital photo archives. This paper aims to be a reference for institutions that plan to manage their digital photo archives so that the digital photo archive is not only stored on the hard disk or server of the institution, but assists in reviving institutional memory that could provide insight.
\end{abstract}

Keywords: digital image, digital image archive, electronic records, EDRMS

\section{Introduction}

The development of photography technology makes it easier for people to produce photos or take pictures, especially digital photos. Few photographers still use analogue cameras; almost all of them have switched to using digital cameras. In addition to the switch from analogue to digital cameras, cameras are themselves increasingly redundant, considering that modern phones can take pictures with their own camera. The convenience ultimately has consequences, and digital photos are generated in huge numbers. Digital photo trends over the last five years show a percentage increase of $9 \%$ per year. The same data shows the number of photos generated in the world during 2016 alone is estimated to be at 1.1 trillion (Perret, 2017). Behind the ease of generating photographs another problem is created; how those digital photographs are managed is a matter that needs to be acted upon. In other words, the photo archive is easy to produce but not as easy to manage.

Not all photos need to be managed, since not all photos have historical value. Photos that have historical value can be called image records, which are worthwhile managing. Image records are part of the audio-visual archive, an archive of information in the form of still images (still visuals). Image records are archives that are generated from either a negative film, digital photos, or positive images or print that are worth preserving (Rusidi, 2009). Not all photos need to be kept; most of them are redundant and do not contain enough information. Selecting appropriate image records is important. Image records with a greater value to an agency or institution ensure a greater level of insurance. An image that is maintained by an agency or institution must possess four basic characteristics to be considered trustworthy. Image records must be authentic, reliable, have integrity, and be usable regardless of the format and the media they are contained in (State of Michigan, 2009)

Authenticity is one of the most important, key features of any record, thus, image records need to be authentic. To ensure the authenticity of a record, the agency should implement and document policies and procedures that control the creation, receipt, transmission, maintenance, and disposition of records. Reliability is the next key element; content must be trustworthy and an accurate representation of the transaction, activities, or facts. Image records must be created at the time of the incident recorded in the photo. The integrity of an image record refers to it being complete and unaltered. Lastly, there is a need to select image records to keep that are usable. In this context, "usable" applies to records that can be located, retrieved, presented, and interpreted.

One of the main reasons for managing image records is to make sure they can be retrieved when needed for any purpose. It is easier to generate metadata for text-based records because the machine can read and index it directly. The image record cannot be described simply by the machine; it takes a human to undertake the description process of the information content contained in the photo. Therefore, the process requires a standard to create a description of the photo, so that no information content is lost from the photo. In this paper, the aspect that is discussed is the description of the digital photo archive. Digital photos can then be said to constitute a photo archive in electronic form. The management of the digital photo archive is slightly different from the management of the analogue photo archive, or one that is still generated in printed form. 


\section{Literature Review}

The purpose of managing photo archives is to create memories and facilitate information retrieval. One of the applications used to manage electronic archives is an electronic records management system (ERMS), i.e., an electronic system for managing records on any media. An electronic system for managing paper records in a records center or registry would be an ERMS. An ERMS could also be a system for managing electronic records, i.e., computerized records. Evidently some standardization of meaning is required before benefits can be identified and measured. An electronic document and records management system (EDRMS) is an integrated system that captures and manages information (Johnston \& Bowen, 2005)

An EDRMS has three main benefits, for the individual user, for the organization, and for society as whole. If we expand on those benefits we can see that an EDRMS helps us to give us information when required. Information as evidence is available. Work is done more quickly and efficiently. Compliance with laws and regulations is achieved and demonstrated. Also, for society, organizational processes are open and can be understood and monitored. Quality of life is improved (Johnston \& Bowen, 2005). The benefits of managing good photo archives include collecting institutional memories, comparing changing times, and are easily accessed when required as evidence. Electronic records have to be actively managed as evidence of business activity, maintaining their authenticity, reliability, integrity, and usability. Much of the functionality required to ensure these things is inherent in the design of business systems and is therefore beyond the scope of this paper, although their importance is acknowledged. The "managing and maintaining records" component of the functional requirements instead focuses on less common functionality (International Council on Archives, 2008)

Atom 2.0 is an open source EDRMS application for managing archives. Atom 2.0 is a web-based archival description software that is based on the International Council on Archives standards. "Atom" is an acronym for "Access to Memory". Implementing the management of digital photo archives will not work properly if the only focus is on the use of the system, regardless of users who carry out the activities of indexing and description of digital photographs. Downing (2006) argues that, for the successful implementation of an EDMS, 20 per cent of effort should be focused on the technology, whereas 80 per cent should be focused on the cultural issues, including the people involved and the business process. McLeod, Childs, \& Hardiman (2010, p. 2) found that "people issues are predominant, fundamental, and challenging as they concern culture, philosophical attitudes, awareness of RM and ERM issues, preferences, knowledge, and skills." This study identified three characteristics relating to the users that may have some bearing on their acceptance of the IT: their digital literacy, personality, and the consistency between their understanding of records management and the structures embedded in IT (Pan, 2017). Ease of use generates more user engagement in the development and implementation of the system.

The description process of image records then generates metadata. Peroses describes archives as "The creation of an accurate representation of a unit of description and its component parts, if any, by capturing, analyzing, organizing and recording information that serves to identify, manage, locate, and explain archival materials and the context and records systems that produced it. This term also describes the products of the process" (ISAD).

\section{Methods}

The method used in this paper is the study of literature. The literature study used is the best practice used in the management of photo archives and metadata standards for photo descriptions. In this paper, the topic is limited to the description of the photo archive, so it does not discuss the acquisition and flow management of photo archives. Another aspect that is limited in this paper is that discussion is limited to the description of digital photo archives.

\section{Results and Discussion}

Digital photos in the form of image records have unique characteristics. Since they do not fall within the category of documents created to represent actions of juridical or legal importance, they display no features that would allow them to be classified according to some type of official criteria. Once produced, they can become part of different sorts or types of documents or they can be used separately, depending upon one's requirements (de Lacerda \& Phillips, 2012). Metadata for records is captured to be meaningful. As evidence of a business process, records must be linked to the context of their creation and use. In order to do this, the record must be associated with metadata about the business context (International Council on Archives, 2008)

There are several different levels of description for the photo archive as Atom itself gives freedom to users to choose the metadata segment used. In addition, Atom takes a template description of some common metadata standards used in the archival world, among others: 
- General International Standard Archival Description: ISAD(G)

- Describing Archives: A Content Standard (U.S.A): DACS

- Dublin Core Metadata Element Set, Version 1.1: Dublin Core

- Metadata Object Description Schema: MODS

- Rules for Archival Description (Canada): RAD

However, standards, as mentioned above, are also commonly used for non-photo archives, or text-based archives, so to describe the special case of a photo archive requires changes or adjustments.

The description of a photo archive, especially on certain metadata segments, requires special expertise and cannot be performed by machines; it can only be done by humans. The descriptions are then downgraded to the metadata of each digital photo archive. Metadata is often interpreted as data about data, which is not wrong, but the meaning of the term is often confusing and ambiguous. Metadata is explicitly the information attached to an entity, so that information can be used for various purposes, one of which is as an access route for data retrieval.

Metadata is captured by systems or by humans, and metadata could be used for systems or humans. On the one hand, a system could create more precise metadata for technical metadata, but on the other hand, humans could do much better in explaining something descriptively. Metadata are divided into different metadata types: descriptive, administrative, rights, technical, structural, behavior, preservation. Metadata in the case of archives or records are referred to as records metadata.

Most archives and libraries are digitizing their batches of metadata for preservation and diffusion. The digital format is in the highest demand and, therefore, the need to better exploit the possibilities that the digital image provides is clear, as far as the insertion of metadata and descriptions is concerned, since providing an image description is far better than naming the file (Romero et al., 2008)

Records metadata is structured information that identifies, authenticates, and contextualizes records, and the people, processes, and systems that create, manage, maintain, and use them, and the policies that govern them. While some records' metadata is captured at the point of the record's creation, metadata continues to accrue over the life of the record. As such, it underpins all records processes. Therefore, functional requirements for records metadata are included in all the outcome areas of this paper (International Council on Archives, 2008).

The description of the photo archive can be divided into three levels; minimum, standard, and complete. Each level has its own weaknesses and advantages. The minimum decryption level produces an item of metadata that is not very complete, so the result in retrieval is not a lot of metadata segments that can be used as access points. But the minimum level of description is easier and faster to do, making it suitable for organizations with fewer archival resources. Conversely, the longest or most complete descriptions will result in many metadata segments that can be used for retrieval, so the retrieval results will be more comprehensive and precise. This is certainly a price to pay, to produce a complete description requiring adequate archival resources, educated personnel, and takes longer to produce archive descriptions.

While the standard description level produces metadata that is adequate for retrieval, it does not require as much archival resources as the full description level. Of course, determining the level of any description is, as far as possible, tailored to the needs and capacities of the organization. The important thing to note is that consistency, regardless of the choice of descriptive level, is maintained as much as possible in use and not easily changing the level of description.

The US National Archives and Record Administration (NARA) recommends minimum elements to describe image archives, as simple as identifier, title/caption, creator and publisher. With complete explanation as follows:

Table 1. NARA Recommended Minimum Elements

\begin{tabular}{|l|l|}
\hline Element & Note \\
\hline Identifier & $\begin{array}{l}\text { Primary identifier should be unique to the digital resource (at both } \\
\text { object and file levels) Secondary identifier might include } \\
\text { identifiers related to the original (such as still picture ID) or record } \\
\text { group number (for accessioned records) }\end{array}$ \\
\hline Title/Caption & $\begin{array}{l}\text { A descriptive name given to the original or the digital resource, or } \\
\text { information that describes the content of the original or digital } \\
\text { resource }\end{array}$ \\
\hline Creator & $\begin{array}{l}\text { (if available) describes the person or organization responsible for } \\
\text { the creation of the intellectual content of the resource }\end{array}$ \\
\hline Publisher & $\begin{array}{l}\text { Agency or agency acronym; description of responsible agency or } \\
\text { agent } \\
\text { Those selected elements serve the purpose of basic identification of } \\
\text { a file }\end{array}$ \\
\hline
\end{tabular}


Source: (Puglia, Reed, \& Rhodes, 2004)

Elements of digital photo archive description from the Yogyakarta DIY Government about the Photos Management Guidelines have a more complete level than the Standard issued by NARA, as for the following details:

Table 2. Yogyakarta Government Minimum Elements

\begin{tabular}{|l|l|}
\hline Element & Note \\
\hline No & Number of photos \\
\hline Issues & Brief explanation of the photos \\
\hline Description & Describes the information and context of the photos \\
\hline Location & Location where photos taken \\
\hline Date & Date when photos taken \\
\hline Image Number & Exact number as file number on folder \\
\hline Code & Initial and serial number description \\
\hline Image Source & Where the photo was retrieved from \\
\hline Photographer & Person who has taken the photos \\
\hline Color or B/W & Black/White or Color Photos \\
\hline Notes & Describes other information besides description \\
\hline
\end{tabular}

A more complete description level, or at the second level of photo descriptions, generally includes descriptive, administrative, and technical metadata within certain limits.

The most complete or highest level of photo descriptions includes all aspects of the metadata of a photo archive. Among them are included aspects of descriptive metadata, administrative, rights, technical, structural, behavior, and preservation. The example of the metadata element in the highest level of description is as follows:

Table 3. Descriptive Metadata Field

\begin{tabular}{|l|l|}
\hline Element Name & Note \\
\hline Primary Identifier & $\begin{array}{l}\text { Unique identifier (numerical string) of the digital image. This } \\
\text { identifier also serves as the identifier for an associated descriptive } \\
\text { metadata record in an external database. May be derived from an } \\
\text { existing scheme. This identifier is currently "manually" assigned }\end{array}$ \\
\hline Secondary Identifier & Other unique identifier(s) associated with the original \\
\hline Title & $\begin{array}{l}\text { Title [informal or assigned] or caption associated with the } \\
\text { resource }\end{array}$ \\
\hline Record Group ID & Record Group Identifier (if known) \\
\hline $\begin{array}{l}\text { Record Group } \\
\text { Descriptor }\end{array}$ & Title of Record Group (if known) \\
\hline Series & Title or Series (if known) \\
\hline Box or Location & Box Number or location (if known) \\
\hline $\begin{array}{l}\text { Structural view or } \\
\text { page (sequence) }\end{array}$ & Description of view, page number, or file number \\
\hline Publisher & Owner or Producer of image \\
\hline Source: Digital Photo & $\begin{array}{l}\text { Generation; Dimensions; Capture Mode/Settings; Quality Level; } \\
\text { Compression Level, etc. }\end{array}$ \\
\hline
\end{tabular}

Table 4. Example of technical metadata used by NARA

\begin{tabular}{|l|l|}
\hline Element Name & Note \\
\hline Copy & $\begin{array}{l}\text { "Role," "function," or "class" of the image (e.g., production } \\
\text { master, delivery, or print-optimized derivative). Currently this } \\
\text { functional designation is also embedded in the file identifier. This } \\
\text { element may serve to indicate the level of preservation service } \\
\text { required }\end{array}$ \\
\hline
\end{tabular}




\begin{tabular}{|l|l|}
\hline $\begin{array}{l}\text { File format } \\
\text { type/version }\end{array}$ & e.g., TIFF, JPEG, PNG \\
\hline Location & Pointer to local file directory where image is stored \\
\hline Image Creation Date & YYYY-MM-DD format \\
\hline Photographer/Operator & Producer of image (name of scanner operator) \\
\hline $\begin{array}{l}\text { Compression } \\
\text { Type/Level }\end{array}$ & $\begin{array}{l}\text { Type and Level of compression applied (Adobe Photoshop- } \\
\text { specific setting as example) }\end{array}$ \\
\hline Color Mode & (e.g., RGB, Grayscale) \\
\hline Gamma Correction & Default Value is 2.2 \\
\hline Color Calibration & $\begin{array}{l}\text { ICC Profile. Default value is Adobe RGB 1998 for RGB images } \\
\text { and Grayscale 2.2 for grayscale images }\end{array}$ \\
\hline Pixel Array & Pixel width $x$ height \\
\hline Spatial Resolution & Expressed in ppi (e.g., 300) \\
\hline Image Quality & $\begin{array}{l}\text { Uses controlled values from authority table. Documents' image } \\
\text { quality characteristics that may influence future decisions on } \\
\text { image value }\end{array}$ \\
\hline File Name & File name of digital image \\
\hline Source Information & $\begin{array}{l}\text { Describes characteristics of the immediate analogue source } \\
\text { (original or intermediary) from which the digital image was made } \\
\text { (see 'Source" in table above) }\end{array}$ \\
\hline
\end{tabular}

The process of creating the photo archive is not a work that everyone can do. The person assigned to run an archive of an agency's photos must be able to sort the photos that should be kept organized. The archivist is often the one person positioned to consider the overall interests and needs of the organization in terms of documentation, accountability, legal purposes, and historical purposes. In addition, the archivist who performs the description activities must be trained well in the activities recorded on the image records. If the archivist is not or is less aware of such activities, he must have access to inquire to witnesses or actors about the activities recorded in the photograph.

Implementing the management of photo archives will usually encounter obstacles in countries that are generally unaccustomed to managing archives well, especially the management of digital archives that are naturally quite different from the management of traditional archives or paper-based media.

Efforts are being made to close the gap with users not familiar with image records, to ensure the records created in the old system will remain available, possess core competencies on how to manage, appraise, acquire, and provide access to electronic records and other digital assets, accept, and implement global standards for archival functions for born-digital records, and formulate appropriate advocacy strategies of the role of information policy in a virtual environment (Asogwa, 2012).

\section{Conclusion}

The ease of technology has consequences in many areas of life. The ease of producing digital photos leads directly to an explosion in the number of photos. Although not all photos must be kept and managed, the number to be processed is still very large. These photographs have the potential to become a recording of history and help form a shared memory. One effort to secure the information aspects contained in the digital image records is to manage it.

The main key to the management of photo archives is in the description. There are many standards that can be used, as well as choice of description level. The more complete the description, the more easily the image records can be retrieved, but this requires more effort in implementation. The simpler level of description is more suitably applied to smaller collections of photos.

One of the applications that can be used to manage digital photo archives is Atom which can be installed and obtained for free. This application gives users the freedom to specify which metadata segments should be listed. The hope is that, with the use of archival information systems, the digital photo archive that continues to be generated does not simply accumulate in the mobile phone memory or hard drive in the computer.

\section{Acknowledgment}

Thank you to Program Studi Manajemen Informasi dan Dokumen for providing laboratory facilities. 


\section{References}

Asogwa, B. E. (2012). The challenge of managing electronic records in developing countries. Records Management Journal, 22(3), 198-211. doi: 10.1108/09565691211283156

de Lacerda, A. L., \& Phillips, D. G. (translation). (2012). Photographs in archives: the production and meaning of visual records. Hist Cienc Saude Manguinhos, 19(1), 283-302. doi: S0104-59702012000100015 [pii]

Downing, L. (2006). Implementing EDMS: Putting people first. Information Management Journal, 40(4), 44-48, 50.

Eric Perret. (2017, October 26). How many digital photos will be taken in 2017. Retrieved April 26, 2018 from https://mylio.com/true-stories/tech-today/how-many-digital-photos-will-be-taken-2017-repost

Gubernur Daerah Istimewa Yogyakarta. Peraturan Gubernur Daerah Istimewa Yogyakarta. (2013). Tentang Pedoman Pengelolaan Arsip Foto. Pub. L. No. Nomor 15. Indonesia.

International Council on Archives. (2008). Principles and Functional Requirements for Records in Electronic Office Environments - Module 3: Guidelines and Functional Requirements for Records in Business Systems. Retrieved from papers3://publication/uuid/1F0F3F47-13F2-4FFC-BAE2-1DB001450B34

Johnston, G. P., \& Bowen, D. V. (2005). The benefits of electronic records management systems: a general review of published and some unpublished cases. Records Management Journal, 15(3), 131-140. doi: $10.1108 / 09565690510632319$

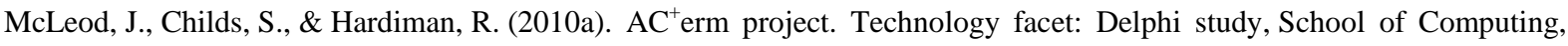
Engineering and Information Science, Northumbria University, Newcastle upon Tyne, Thematic analyzes. Retrived from www.northumbria.ac.uk/acerm (accessed April 24, 2013)

Pan, W. (2017). The implementation of electronic recordkeeping systems: An exploratory study of socio-technical issues. Records Management Journal, 27(1), 84-98. doi: 10.1108/RMJ-04-2016-0014

Puglia, S., Reed, J., \& Rhodes, E. U. S. (2004). Technical guidelines for digitizing archival materials for electronic access : Creation of production master files--raster images. Digital Library Federation.

Romero, N. L., Chornet, V. V. G. C., Cobos, J. S., Carot, A. A. S. C. S., Centellas, F. C., \& Mendez, M. C. (2008). Recovery of descriptive information in images from digital libraries by means of EXIF metadata. Library Hi Tech, 26(2), 302315. doi: $10.1108 / 07378830810880388$

Rusidi. (2009). Pengelolaan arsip foto.

State of Michigan. (2009). Best Practices for the Capture of Digital Images form Paper or Microfilm. Michigan, USA. 